\title{
NASA-NPS LANDSCAPE CLIMATE CHANGE VULNERABILITY PROJECT (LCCVP) TEAM MEETING AT AMK RANCH (UW-NPS RESEARCH CENTER)
}

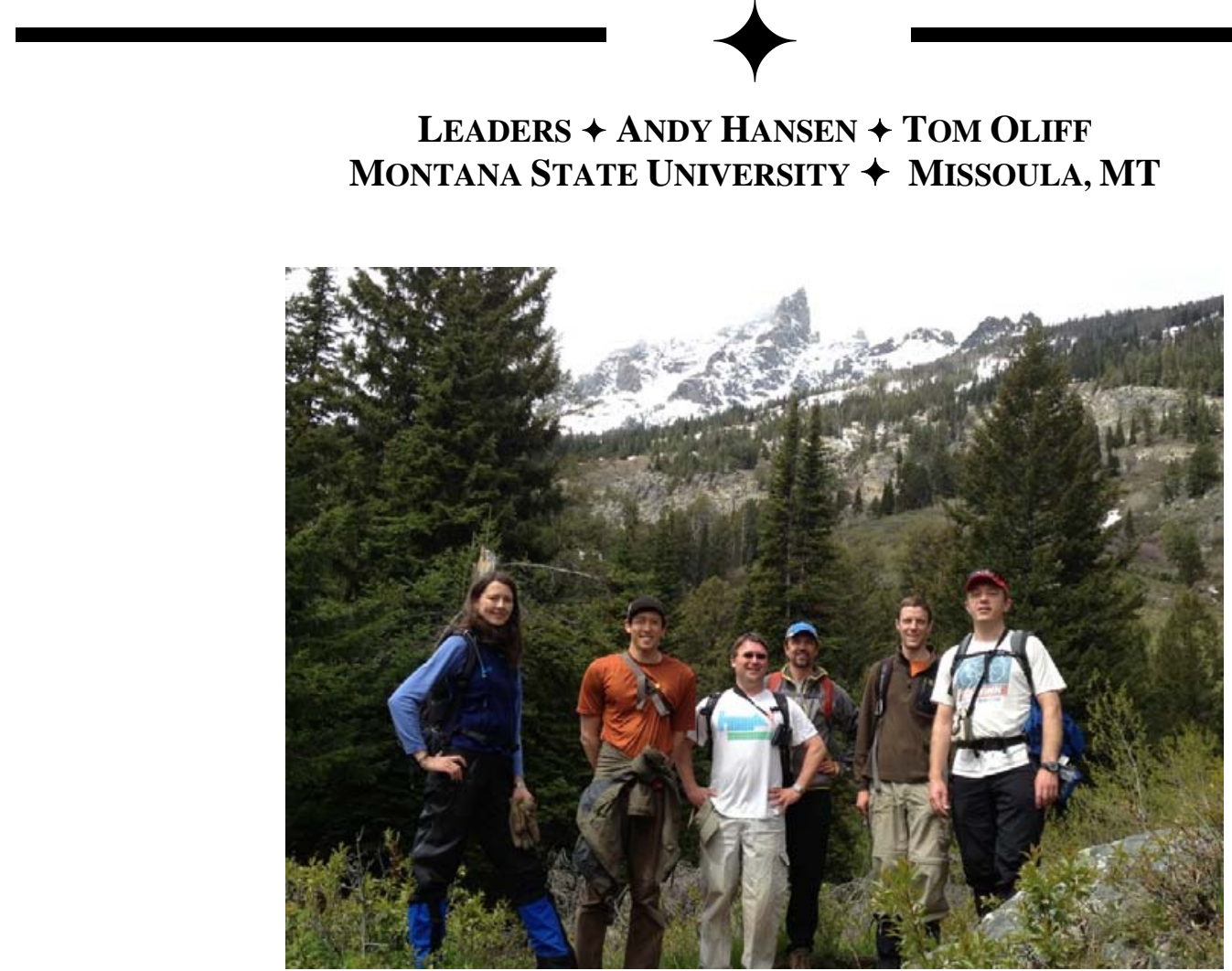

Figure 1. A portion of the team hiking up Cascade Creek.

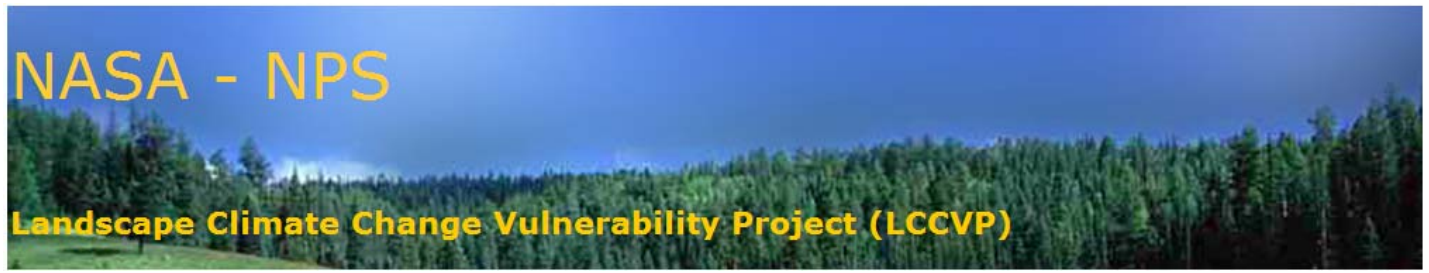

A NASA-funded research team met May 1922 at the AMK Ranch for a semi-annual team workshop.

Participants included:

Montana State University - Andy Hansen, Tony Chang, Regan Nelson, Nate Piekielek Woods Hole Research Center - Patrick Jantz, Scott Zolkos
NPS Inventory \& Monitoring Program John Gross, Bill Monahan

Great Northern LCC - Tom Olliff

NASA Ames - Forrest Melton, Jun Xiong

Guest - Steve Running (University of Montana)

Chef - Jodi Stevens 
The goal of the project is to demonstrate the four steps of climate adaptation planning in two US Department of Interior Landscape Conservation Cooperatives (LCCs) using NASA and other data and models. Objectives are:

1. Hindcast and forecast future climate and land use scenarios.

2. Assess the vulnerability of ecological processes and key habitat types.

\section{Evaluate management options.}

4. Design and implement management adaptation strategies.

\section{Facilitate decision support.}

Designation of DOI LCCs emphasizes the threat that climate and land use change pose to biological resources in national parks and federal lands. Developing strategies for management and adaptation requires the ability to forecast biological response under future scenarios, assess the vulnerabilities of biological resources, and designing multi-scale management strategies. This project focuses on portions of the Great Northern and Appalachian LCCs, which have already undergone climatic warming. Within the climate adaptation framework of Glick et al. 2011, we are using the Terrestrial Observation and Prediction System (TOPS) and the SERGoM land use change models to hindcast (2001-2010) and forecast (2010-2100) responses of habitat types to future climate and land use scenarios. Results are being used to assess vulnerability and to place indicators into management classes: Low Risk (management not needed); Manageable (management effective and required); and Save at High Costs (management costly, high risk). For Manageable issues, the team is designing spatially and temporally explicit management strategies to improve resilience and/or adaptation. This project will help prioritize future activities within the two case-study LCCs and provide a demonstration that may lead to application nationwide.

The project is nearly half way through the 4year funding period. The purpose of the team meeting was to review progress to date and plan for upcoming activities. We convened the evening of May 19 with a fascinating introduction to the AMK by Hank Harlow. This was followed by a discussion lead by climate scientist and global ecologist Steve Running. The group had a wonderful day-long hike up Cascade Creek in the shadow of the Grand Teton on May 20. Our main work session was on May 21 at the AMK, but we were careful to leave time for a short hike to Grand View Point in the evening. The workshop was concluded on May 22 with a meeting at Grand Teton National Park Headquarters with GTNP and Bridger Teton National Forest Staff. The AMK was an outstanding setting for stimulating creative thoughts and fostering group synergy. Meals by Chef Jodi Stevens were wonderful. More information on the study can be found at:

http://www.montana.edu/lccvp/index.html.

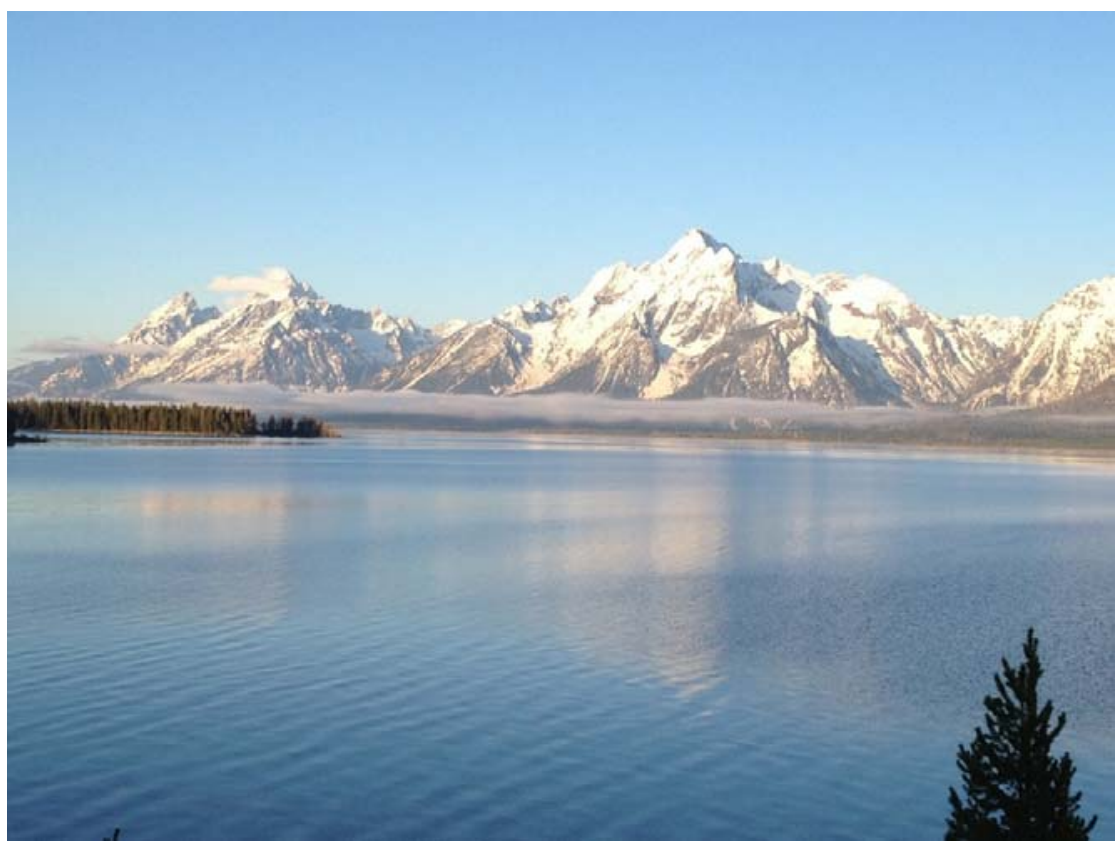

